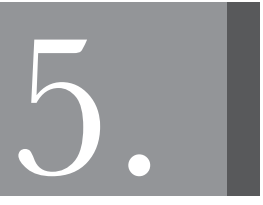

\title{
Los modelos asimétricos aplicados al terrorismo
}

Federico Aznar Fernández-Montesinos*

\subsection{Introducción}

El siglo XXI, un siglo, hasta el momento sin grandes transformaciones conceptuales, ha estado marcado por el desarrollo de las ideas de finales del siglo pasado (Aznar, 2013, p. 2). Como resultado un mundo poliédrico acaba proyectándose sobre un único plano generando una situación nueva y múltiples incertidumbres (Aznar, 2013, p. 2).

Las instituciones son hijas de su tiempo (Aznar, 2013, p. 7). Una de esas instituciones, que sin duda, es la guerra, que estampillada por el pensamiento de los hombres que la llevan a cabo no pierde por ello sus esencias; la guerra evoluciona con el hombre y en ella se inscriben todas las formas de violencia organizada (Aznar, 2013, p. 7). Es territorio de crueldad (Aznar, 2013, p. 7). Pero, no se olvide, también lo es de encuentro (Aznar, 2013, p. 7).

\footnotetext{
* Capitán de Coberta Instituto Español de Estudios Estratégicos
} 
Si la guerra es un acto de comunicación, una dialéctica, con un suplemento de violencia, el terrorismo es, parafraseando a Mao una actividad política escenificada mediante un cierto derramamiento de sangre. El terrorismo es, por tanto, al igual que la guerra y por muy ilegítimo que resulte, una herramienta de la política a la que cabe definir como el empleo (o la amenaza) de la violencia en apoyo de un concreto proyecto político. Son actuaciones tácticas diseñadas para influir políticamente.

En fin, el nuevo siglo se iniciaba de un modo tempestuoso que conviene analizar detenidamente para tratar de comprender cómo ha evolucionado la guerra, como una adaptativa dialéctica de voluntades hostiles, de la que se derivan los conflictos asimétricos presentes y, entre ellos, singularmente, el terrorismo (Aznar, 2013, p. 2).

$\mathrm{Y}$ es que el terrorismo es un fenómeno que, como la guerra, acompaña al hombre desde su aparición. Miedo y terror son los nombres de los hijos de Ares, dios de la guerra. Pero el terrorismo ha experimentada todo una evolución, un proceso de cambio y transformación derivado a que una de sus principales características es la originalidad. La base del terrorismo es la sorpresa; y la sorpresa precisa de originalidad.

$\mathrm{Y}$ es que el fenómeno terrorista persiste mientras cambia; y no deja de sorprender, tanto por la continuidad de los procedimientos con los que se manifiesta como por su capacidad para adaptarse a los entornos cambiantes, reinventándose permanentemente a sí mismo.

Por eso, entre otras razones, ninguna definición de terrorismo recoge toda la casuística que se ha generado a lo largo de la historia, incluyendo aquellos casos aparecidos antes de la propia definición del concepto. Dicho lo cual y si para entender plenamente cualquier proceso resulta obligado comprender el entorno en que ha tenido lugar, esto en el terrorismo es imperativo dada su naturaleza metamórfica. Hay que entender el marco.

\subsection{Las claves del nuevo siglo}

Un vuelo a vista de pájaro sobre el tablero del siglo XXI nos muestra las complejidades generadas por el nuevo estadio en las relaciones inter- 
nacionales, la incertidumbre de una amenaza no definida ni concretada, o las contradicciones derivadas del diferente nivel de desarrollo de países que súbitamente se han puesto en contacto.

Las esquinas del puzzle internacional en sus albores se encuentran en cuatro factores clave: la sombra de la Guerra Fría, una globalización incompleta, la falta de consideración hacia el otro cultural, y la visualización del mundo en clave religiosa, una auténtica geopolítica de las religiones.

\subsubsection{La sombra de la Guerra Fría}

El año 1989 es un año clave, decisivo, en la historia de la humanidad (Aznar, 2013, p. 3). El arco gótico sobre el que se había construido las relaciones internacionales y que había permitido casi cuatro decenios de estabilidad internacional se desmoronaba (Aznar, 2013, p. 3). Existían rivalidades, pero las grandes líneas que apuntaban a amigos y enemigos estaban claras; y por debajo del arco había un espacio bien definido y fiable para la política (Aznar, 2013, p. 3).

Muchas sociedades, estabilizadas por la presión recibida de ambos bloques se descompusieron. Como consecuencia se produjo una creciente fragmentación y diversificación de una violencia que, además, multiplicó sus actores y formas. Esta multiplicidad, es reflejo de la variedad de identidades, motivaciones, intereses y niveles de actividad de los actores; en un único conflicto puede haber violencia de la insurgencia, terrorismo, étnico-confesional, intercomunitaria, tribal o criminal.

Pero aún quedan ecos de las viejas desconfianzas, miradas recelosas que entienden que la superación de las diferencias ideológicas no supone la resolución definitiva de unas causas del enfrentamiento que son geopolíticas. El resultado es que, la sombra de los antiguos bloques se extiende sobre el escenario de las relaciones internacionales. La guerra de Georgia en 2008, primero, y la ocupación de Crimea, después, volvieron a señalar a Rusia como necesario relevo geopolítico de la URSS y las viejas formas de la Guerra Fría volvieron a reproducirse nuevamente.

Y además el comunismo no ha desaparecido completamente (de hecho es comúnmente aceptado en Occidente) y en el Tercer Mundo se ha 
fusionado con signos de pensamiento local, generando formas sincréticas que aparecen desde movimientos revolucionarios del tipo de Sendereo Luminoso, hasta formas ecuatoriales de populismo, pasando por las ideologías de ruptura hechas a partir de la reelaboración revolucionaria de las creencias tradicionales en un marco de miseria (Aznar, 2013, p. 3).

Pero Occidente había completado sus debates y tenía una propuesta a la que pretendía dotar de validez universal (Aznar, 2013, p. 3). La economía de mercado y la democracia se perfilaban como los grandes vencedores de la Guerra Fría (Aznar, 2013, p. 3). Su formulación se hizo comprometiendo la absoluta independencia de los Estados que conceptualmente había imperado desde Westfalia (Aznar, 2013, p. 3).

Cuando Occidente asume esta carga y entra en los conflictos surgidos en países con un diferente estadio de desarrollo aparece la guerra asimétrica. El fenómeno que permitirá considerarla como de Cuarta Generación, es la globalización que relaciona sociedades con ejes referenciales distintos, produciendo el retorno al hombre y un modo de hacer la guerra. El terrorismo global puede inscribirse en esta dinámica. Además, el mundo se cierra sobre sí mismo, las fronteras se hacen comunes, la interacción de todos con todos se incrementa y con ella los conflictos.

La Primera Generación de guerras estaría marcada por el desarrollo y consolidación del concepto Estado durante el Renacimiento, serían guerras limitadas hechas por soldados profesionales; las guerras de Segunda Generación implicarían el compromiso societario en la causa y sus epitomes serían la Revolución Francesa (que ampliarían los objetivos políticos) y las revoluciones industrial y de los transportes (que dotaron de más medios técnicos precisos para llevarlos a cabo) en una marcha desde la guerra limitada a la total y absoluta; las guerras de Tercera Generación se fundamentan en la tecnología y tratarían de ser resolutivas disminuyendo la efusión de sangre y volviendo de nuevo al terreno de lo limitado.

\subsubsection{La globalización como fenómeno incompleto}

La globalización ha sido el gran fenómeno de este siglo, no porque sea nuevo; podemos rastrear los comienzos de esta fase en el siglo 
XV-XVI con el descubrimiento de América y las luchas de Carlos V, su intensificación en el XIX con la Revolución de los Transportes o los conflictos mundiales del XX (Aznar, 2013, 4). Es pues, ante todo, una tendencia histórica no referida solo a la economía que va asociada a un incremente geométrico en la intensidad de las relaciones y que ahora ha entrado en vorágine (Aznar, 2013, p. 4).

Una globalización que, si por una parte ha maximizado los beneficios, por otra ha supuesto la desaparición de los compartimientos estancos de las sociedades e incrementado su vulnerabilidad (Aznar, 2013, p. 4). Los Estados son interdependientes; y una sola caída es un cataclismo. El mundo se ha cerrado y los problemas locales, las agendas, se han globalizado al coincidir mundos premodernos y posmodernos (Aznar, 2013, p. 4).

Mundos que viven en tiempos distintos entran en contacto directo, sin intermediadores, de sociedad a sociedad, de persona a persona (Aznar, 2013, p. 4). El otro inspira desconfianza tras la que asoma siempre el temor. Un temor real en la medida en que la globalización puede suponer la destrucción de las formas culturales más débiles (Aznar, 2013, p. 4).

La relación directa es beneficiosa pero también es una fuente de conflictos. Y es que la globalización promueve una distribución horizontal del poder, su atomización; se reducen las distancias geográficas y se simplifican muchos procesos, pero simultáneamente, también se hace más difícil la gobernabilidad política; implica interconexiones e interdependencias, pero no acuerdos, es más, ni siquiera la confluencia de pareceres con lo que, en la práctica, se promociona la reacción, el localismo, la definición contra el otro (Aznar, 2013, p. 4).

Implica, pues, la puesta en marcha de procesos de racionalización a los que sigue la oposición antitética de los que la máquina va a terminar inexorablemente por racionalizar (Aznar, 2013, p. 4). Con lo cual, aun sin presentarse como tal, el otro cultural, el poderoso, es percibido como agresor y su presencia considerada intolerable (Aznar, 2013, p. 4). La conectividad que la caracteriza tiene ese inconveniente.

Como consecuencia, el mundo de la globalización es un mundo muy fragmentado que obliga a vivir en la pluralidad, en una heterogeneidad por el momento sin solución. Globalización no implica un pensamiento 
único - tal vez a la finalización del proceso, con la racionalización- sino, en realidad, confrontación de pareceres (Aznar, 2013, p. 4).

\subsubsection{Falta de consideración hacia el otro cultural}

Para que exista una guerra primero tienen que existir grupos humanos diferenciados, después, estos grupos tienen que relacionarse. Y es que, la guerra es por encima de todo una forma de relación. Entre quienes no hay relación, no hay guerra.

Los elementos que han permitido la separación entre grupos humanos han sido los cleavages; etnia, lengua, religión y cultura (Aznar, 2013, p. 5). A ellos se añaden las instituciones creadas por los propios hombres y con sus intereses particulares, los Estados (Aznar, 2013, p. 5). Parece haberse producido un retorno de la sacralidad a sus fuentes abandonando espacios que no le eran realmente propios como la nación (Aznar, 2013, p. 5).

Las culturas presentan un sistema de valores completo, único, cerrado, una forma de ver el mundo, que no son constantes en el tiempo sino que varía en cada época (Aznar, 2013, p. 5). Entiéndase, los valores prácticamente son los mismos, sin grandes modificaciones: lo que varía en cada una de las culturas es su ordenación, el sistema de valores (Aznar, 2013, p. 5).

El etnocentrismo presenta lo propio como natural y lógico, transparente al usuario, mientras lo ajeno resulta extraño, extravagante, cuando no una agresión. El resultado es que las culturas han vivido de espaldas unas a otras, sin intercambios, amparadas por algún accidente geográfico que lo permitía. A esta diferencia y a distintos conflictos locales como el israelopalestino se añaden conflictos por el reparto de la riqueza y las diferencias socioeconómicas.

Occidente ha exportado su modelo, su apuesta. La democracia y la economía de mercado, como si se tratara de absolutos éticos, esto es, sin tener en consideración al otro cultural, sin tener en cuenta que estas instituciones estaban impregnadas hasta el tuétano de sus códigos axiológicos, y que su presentación podía subvertir el orden establecido en el otro mundo cultural. Más aun, ha hecho llegar al otro cultural a través de 
los medios de comunicación de masas su estilo de vida, su éxito mientras se le hacía sentir, en la intimidad de su hogar, lo suyo como un fracaso. El contacto es inevitable, y el juicio también.

La colonización, sin duda, fue un proceso traumático; las luchas por la independencia ocasionaron una violencia que Franz Fanon tilda de liberadora (Aznar, 2013, p. 6). Pero es que la descolonización fue un nuevo trauma al quedar los nuevos Estados frente a su incompetencia, al no mostrase capaces de asumir los modos occidentales de producción (Aznar, 2013, p. 6). Y el advenimiento de los medios de comunicación de masas puso a las sociedades del Tercer Mundo en comunicación directa con las sociedades de Occidente, cerrando el círculo del mutuo conocimiento (Aznar, 2013, p. 6). La alienación y la humillación cultural constituyen un caldo de cultivo del que es siempre posible que fermenten grupos terroristas (Aznar, 2013, p. 6).

Merece la pena considerar cómo Occidente se fio por completo de su superioridad tecnológica hasta en la guerra, ignorando las sociedades sobre las que actuaba (Aznar, 2013, p. 6). Ni Irak ni Afganistán fueron objeto del estudio, detalle que merecían, y los resultados de ese error son bien conocidos (Aznar, 2013, p. 6). La diferencia de culturas se traduce en diversos modos de hacer la guerra, y por tanto en una asimetría esencial en las estrategias fruto de un diferente enfoque del problema militar (Aznar, 2013, p. 6).

\subsubsection{Una visión del mundo en clave religiosa}

La religión es un elemento clave en la adscripción cultural de las poblaciones, en su vida privada y en sus relaciones sociales. No obstante, ha sido llamado "el factor olvidado" de las Relaciones Internacionales, porque estas han tendido siempre a explicarse con base en intereses, sin mayores consideraciones. Tras el 11-S se produjo el retorno de la sacralidad que se había transferido a conceptos como la nación, a su ámbito específico, a la religión. La cuestión es sí ese retorno ha sido real o por el contrario, y como parece, las relaciones internacionales nunca han dejado de estar guiadas por los intereses, pese al fogonazo del 11-S (Aznar, 2013, p. 6). 
En cualquier caso, el 11-S hizo que el mundo se interpretase, se explicase, súbitamente en clave religiosa (Aznar, 2013, p. 6). Sus imágenes han quedado impresas en la memoria colectiva, originando una reinterpretación del mundo (Aznar, 2013, p. 6).

No obstante, los occidentales abominaron de Huntington oficialmente (Aznar, 2013: 6). Y es que no hacerlo así es convertirse en enemigo de aproximadamente 1200 millones de personas, lo cual no resulta, en principio muy inteligente; y es precisamente lo que quieren los radicales que defienden sus postulados (Aznar, 2013, p. 6). Aunque la verdad es que en la práctica Huntington ha sido aceptado por todos (los radicales lo reclaman para sí públicamente), por más que no se reconozca oficialmente (Aznar, 2013, p. 6).

\subsection{El terrorismo como fenómeno asimétrico}

Las grandes epopeyas siempre las han escrito los débiles. La historia siempre recoge la experiencia de naciones fuertes derrotadas por enemigos más débiles que supieron hacer un uso más eficaz del poder y al hacerlo legitimaron su causa. Y es que, no pueden olvidarse los casos de grupos terroristas que han alcanzado el poder y, desde la legitimidad de la victoria han reescrito su historia haciendo olvidar la sangre indebidamente derramada al poner los focos sobre los aspectos heroicos de su proceder.

La decisión sobre la estrategia por utilizar en un conflicto afecta a su esencia. Es evidente que son los factores estratégicos (medios, objetivo, reglas, riesgos) los que orientan la decisión, pero no la determinan. Así de factores similares no se derivan decisiones estratégicas similares ni de factores estratégicos distintos se desprende necesariamente divergencia estratégica y por tanto asimetría (González, 2009).

El terrorismo comparte con la guerra asimétrica estos factores esenciales; la diferencia de capacidades de las partes, una lucha realizada adoptando modelos estratégicos particularmente diferentes; el uso de medios alternativos no convencionales; la utilización de las limitaciones de la otra parte (el Estado de derecho y la religión), la diferencia de riesgos entre las partes: un terrorista, equivocado o no, arriesga más que un 
soldado, arriesga no solo su vida sino su honor, su casa y hasta la vida de su familia.

\subsubsection{El problema de su definición. Características principales}

Definir un concepto, social conceptualizar, es dotarlo de límites; y los límites en la sociedad se construyen desde los consensos. Tratar de consensuar algo que pertenece a la esencia de un conflicto vivo es difícil, lo que explica la no existencia de una definición de terrorismo aceptada internacionalmente.

En estos casos, la polisemia es un instrumento muy útil. Con la palabra terrorista se incluyen realidades muy heterogéneas de modo que su definición condiciona el resultado, cuando el resultado deseado no condiciona la definición. Al final lo que se hace son listados ad hoc de organizaciones terroristas por parte de organizaciones internacionales.

Terrorista puede ser un adjetivo o un sustantivo, una persona, una situación, un proceso, un hecho o una estructura (Aznar, 2013, p. 9). Y la cuestión no es baladí, un detenido puede ser un delincuente, un soldado, un terrorista según el nombre que se dé al conflicto, o según el que la comunidad acepte (Aznar, 2013, p. 9).

Y, además, siempre es posible el deslizamiento de unos términos que pasa inadvertido a la opinión pública. No obstante, es muy relevante y no solo desde el punto de vista académico. Tras la guerra de Kosovo, un movimiento catalogado de terrorista, el UCK (o ELK), ha sido la base de las nuevas fuerzas policiales. Otro tanto puede decirse de grupos terroristas israelíes durante la dominación inglesa o del FLN argelino. Michael Collins pasó de ser el líder militar del IRA a Ministro de Defensa.

La clave se encuentra en domesticar la frontera, lo que se consigue haciendo que los conceptos sean de geometría variable. De ahí la eficacia en utilizar para afrontar los cuerpos de seguridad militarizados, para los que no existe la frontera interior (como cuerpos de seguridad) ni exterior (como FAS) ni tampoco diferencias conceptuales relevantes (terrorista, soldado, delincuente...), el campo de batalla es continuo, sin saltos. 
Se trata de un combate expresivo, simbólico, una violencia con la que se pretende reclamar la legitimidad de una causa, erigirse en representante de la sociedad, poseedor de la verdad y vengador de sus agravios. El terrorismo es ofensiva, una actividad del espíritu, de voluntad, llevada a cabo por personas fuertemente motivadas. Con él se pretende secuestrar la imaginación del colectivo que asiste como espectador a su actividad, pero que realmente también está incluido en la obra que se representa.

El terrorismo es la esencia de la violencia del nuevo milenio. De hecho, en 2006, el número de actos terroristas, entre los contabilizados hasta ese año, fue el más alto de la historia, con 6500, con un incremento del $30 \%$ sobre 2005 y 3,7 veces mayor que el de 2001; el número de muertos en 2006 fue de 12.000, un 46\% más que en 2005 y 2,6 veces más que los producidos en 2001 (David, 2008, pp. 42-43). Casi la mitad de los conflictos a lo largo del siglo XX han sido ganados por quienes han sido juzgados como más débiles.

No obstante, en palabras de Moisés Naím (2016): "Los números del terrorismo son relativamente bajos cuando los comparamos con otras causas de muerte. Pero sus consecuencias son desproporcionadamente grandes". El portal Statista ha publicado recientemente un estudio que muestra que a pesar de los ataques terroristas en suelo europeo, el número de personas asesinadas por terroristas en los países de la UE en los últimos 12 meses, es inferior a las cifras que se registraron en las décadas de los años setenta y ochenta del pasado siglo ${ }^{1}$. En Londres en el contexto de la Segunda Guerra Mundial, que un día solo cayera una bomba, hubiera permitido a los niños ir al colegio.

A la contra la violencia forma parte del terrorismo, pero el terrorismo no es solo violencia; de hecho, lo más importante del terrorismo no es la violencia - que es su manifestación más visible- sino su discurso; la misma relación que existe entre el cáncer y la fiebre; y es que el maquiavelismo de la estrategia equivoca fuerza con poder.

1. En https://www.statista.com/chart/4093/people-killed-by-terrorist-attacks-in-wes tern-europe-since-1970/ (Recuperado el 27 de marzo de 2016). 
Su popularidad se debe a que puede paralizar o influir en los más poderosos sin muchos recursos, a través del empleo de medios no convencionales, haciendo que no haga falta ser fuerte para cambiar la historia gracias al efecto multiplicador de los medios de comunicación. El poder es ante todo imagen y el terrorismo provocación. El acto terrorista, además de cuestionar la capacidad del Estado para cumplir su función, expresa voluntad, ideología, potencia y medios.

Su naturaleza clandestina permite evitar la lucha abierta, el enfrentamiento directo. Es un humanismo, por cuanto dice respetar la vida humana en la medida en que ello resulta posible; su carácter ruidoso esconde la debilidad de quien aspira a que su fuerza sea magnificada, amplifica la capacidad militar real enmascarando la dimensión de la asimetría al ofrecer resultados importantes utilizando medios escasos (Calvo, 2004, p. 40). El problema de los revolucionarios puede ser que crean en la materialidad del propio ruido y pierdan la perspectiva de su importancia real.

En su estadio actual, es una amenaza de naturaleza dual -civil y militar- que incita a una respuesta militar, pero su importancia es relativa si se compara cuantitativamente con la violencia de la guerra.

Debe quedar claro, ya en su definición, que el terrorismo puede ser considerado como una forma de guerra limitada en cuanto a los objetivos que persigue y en cuanto a los medios que emplea para tal fin (Aznar, 2011, p. 2). No se trata de una estrategia decisiva.

Y es que cada atentado es algo más que una acción entre otras (Aznar, 2012, p. 7). El valor de un atentado no lo mide el número de muertos que provoca o sus efectos materiales; el criterio definitivo de valoración se establece en términos de impacto mediático primero y psíquico después (Aznar, 2012, p. 7). No trata de destruir las fuerzas enemigas, ni siquiera de hacer inoperantes sus medios, sino de humillar, de quebrantar la voluntad de lucha, de influir sobre los que tienen que tomar las decisiones (Aznar, 2012, p. 7).

La violencia impregna los discursos tiñéndolos de sangre; pese a ello son discursos, no batallas. Su clave es la explotación de los medios de comunicación; es la "propaganda por el hecho". Por eso las cifras no son 
suficientes para explicar que sus efectos van más allá del daño real que producen. Su valor no se mide por el número de muertos que provoca o por sus efectos materiales; sino en términos de impacto mediático primero y psíquico después.

La complejidad de las sociedades desarrolladas las haría más débiles que las no desarrolladas; las sociedades desarrolladas se adaptan peor que las no desarrolladas a la incertidumbre de la guerra. El hombre posmoderno soporta peor el desorden en su complejo entorno y la inseguridad que el primitivo (González, 2009).

El terrorismo es espectáculo y un fenómeno fundamentalmente urbano (los teatros están en las ciudades, no en los pueblos). 50 muertos en la selva no tienen la misma repercusión que uno solo en una ciudad. El eco de las bombas se escucha mucho más en suelo urbano, en las cajas de resonancia de los medios de comunicación.

El terrorista se presenta a sí mismo como un soldado, aunque sus actuaciones no se ciñan a la metodología de los soldados o a la ética del guerrero, ni asuma las limitaciones que impone el Derecho Internacional Humanitario y sean crímenes. Pero tampoco se confunde con un delincuente común, cuyas acciones están orientadas a un fin concreto; la diferencia se encuentra en la ideología (Aznar, 2009, p. 194).

Por razones operativas, el número de terroristas de un grupo concreto no puede ser grande, de no ser así perdería su carácter secreto y sería vulnerable policialmente. Es decir, por razones operativas debe conservarse débil (como decía Lao Tse "conservarse débil se llama fortaleza"), lo que condiciona tanto sus estrategias que solo pueden ser indirectas -no cabe el enfrentamiento frontal- como sus fines que no pudiendo ser la victoria, son limitados y pasan siempre por la negociación. Además, los terroristas no cuentan las más de las veces con la preparación adecuada para gestionar esa victoria.

Mientras la estrategia clásica se funda en criterios de eficacia, medido en los objetivos conseguidos, el terrorismo sigue criterios de eficiencia, que el tiempo hará eficaces. Por ejemplo, Ben Laden cifra el coste del atentado de 2001 en 500.000 dólares; sin embargo, es estima que causó daños en 500.000 millones (Lawrence, 2007, p. 292). Pero las 
medidas dirigidas a impedir una nueva actuación de este tipo resultan mucho más onerosas.

Toda vez que la parte más débil lo es siempre en el terreno militar, este plano pierde importancia, ya que esta parte rechaza enfrentarse a él y busca otros espacios alternativos. Si la guerra se hace horizontalmente buscando esa superioridad militar, ahora se va a realizar verticalmente y en otros planos (político, social, de los medios de comunicación, económico $[\ldots])$. Además, los grandes no saben hacer guerras pequeñas ni cuentan con la paciencia precisa (González, 2009), es eficacia frente a eficiencia.

El objetivo del acto de violencia no representa el objetivo principal sino que es un medio para la transmisión de un mensaje. El resultado de la dialéctica entre el pensamiento y la acción en la concepción terrorista es el atentado que resulta, en cierto modo una pregunta, el planteamiento de una cuestión que, por los términos en que se formula, obliga a una respuesta

La población es objeto y objetivo de la lucha. El agitador no conquista al pueblo, presenta sus actos como la realización de sus deseos no formulados, despierta su conciencia dormida. Por eso debe diferenciarse al terrorista de la población. Confundirlos es atender a su juego y permitirle alcanzar su objetivo: presentar su discurso como el del conjunto, la fuerza de su pequeño grupo con todo un movimiento social. Las narrativas son claves en este proceso (Aznar, 2012, p. 1).

En Argelia, ni la guerrilla de montaña ni la clandestinidad de las ciudades ganaron la guerra en el sentido militar del término, pero aunque se apagara el incendio inicial, este siempre resurgía a la menor oportunidad, forzando a los invictos franceses a abandonar (Aznar, 2011, p. 431). La razón era clara, no se trataba de un problema militar ni policial, sino de un problema político; el movimiento terrorista había cuajado en la población fundiéndose con aquella y generando un movimiento social, una auténtica marea humana frente a la cual los resultados del empleo de la fuerza eran limitados (Aznar, 2011, p. 431).

El terrorismo es, pues, un método, una herramienta en la que convergen acto político y acto de terror, violencia legítima e ilegítima, la 
ética y la interpretación propia del público receptor. Con el terrorismo la política se hace violencia y la violencia pedagogía, una pedagogía con la que enseñar al pueblo. El terror es también el medio de construir y hacer llegar un mensaje.

El terrorista tiene ventaja; su discurso, simple, reiterado es un discurso comprensible, lo que le confiere ventaja desde la perspectiva de la comunicación política. Y como la audiencia no juzga tanto los fines pretendidos por las partes como el estadio actual del conflicto y sus medios, la batalla por la opinión pública se torna difícil, máxime cuando no se consiguen explicar las razones propias por la ingente cantidad de flecos que acompañan a la realidad; una realidad que precisa no de blancos y negros sino de toda la escala cromática (Aznar, 2012).

\subsubsection{Narración y discurso}

El terrorismo conlleva implícitamente una estrategia de comunicación que incluye negación y propaganda. Si los discursos son trascendentes en la guerra asimétrica, el terrorismo no es sino discurso. Pero también es negación no construcción, razón por lo que debe formar parte de una estrategia más amplia que apoyen su naturaleza como medio para un proyecto ilusionante indisolublemente ligado a la acción política: nuevamente un discurso. Por eso tiene más fortuna cuando se combina con otros métodos como la constitución de un partido político, un movimiento de masas o una organización social (Waldmann, 2006, p. 125).

$\mathrm{El}$ atentado sirve para plantear un problema, lo hace visible. Los medios lo explican, intentan hacer comprensibles sus planteamientos. La reiteración hará que lo inusitado resuene aunque sea con repugnancia.

Repite y repite hasta transformar en usual lo inusitado, y construir su discurso en torno a ello. De esta manera la violencia, la reiteración y el tiempo servirán para hacer pedagogía. Después, la erosión otra vez del tiempo y la propia sangre servirá para limpiar la causa. Y lo que una vez sonó como imposible, será primero posible, después deseable y por último hasta justo. Dieciocho meses después de los atentados de Munich, Yassir Arafat fue invitado a hablar ante la Asamblea General de la ONU (Hoffman, 1999, p. 100). 
Son pues estrategias de largo plazo, deliberadamente prolongadas en el tiempo que toman de la política la perseverancia y la repetición con objeto de hacer que cale su mensaje. La clave se sitúa en la pedagogía, en la violencia expresiva, con el terror se enseña y la fuerza hace que todas las empresas parezcan justas.

Se precisa recordar, recrear, imaginar para que unos actos cuyo rasgo más sintomático es su bajo riesgo real, puedan amedrentar a toda una comunidad. Se trata de colonizar las mentes, conmocionar y a través de la conmoción dominar a la opinión pública.

La población se convierte en objeto y objetivo de la lucha. La fuerza es violencia cuando no cuenta con legitimidad y autoridad en caso contrario. El debate que el terrorismo plantea gravita entorno a la legitimidad. Las acciones terroristas son acciones de alto contenido simbólico que pretenden demostrar la capacidad y representatividad del grupo que se presenta como el brazo armado de una sociedad (o de parte de ella) y expresión de su legítima voluntad (Aznar, 2014, http://www.ieee. es/Galerias/fichero/OtrasPublicaciones/Nacional/2015/Libro-CESEDEN_GuerracontralaViolencia_FAFM.pdf).

Por eso el terrorismo dosifica y modula la violencia en dosis homeopáticas atacando los nodos de la sociedad y el Estado para propiciar su transformación. Su sola existencia es un cuestionamiento del orden vigente. En palabras de Raymond Aron (1993, p. 143) "los guerrilleros ganan la guerra cuando no la pierden y quienes luchan contra ellos la pierden si no la ganan".

Todas las acciones terroristas deben formar parte de la línea de pensamiento escogida, puesto que su utilidad militar es limitada. Los actos (sean o no de fuerza) son algo más que sucesos, son preguntas y respuestas a un tiempo y responden a la causa original a la vez que generan un estadio nuevo, un nuevo punto de partida. El conflicto es así discursivo ideológica e instrumentalmente en la medida en que los sucesos se integran en él. El terrorismo chechenio primero fue nacionalista, después su fundamento fue religioso. Pero lo que importaba era que la violencia fuera cual fuera su origen se mantenía inalterada, alimentándose en parte de las reacciones. Primaban los hechos sobre las teorías. 
En la guerra convencional, tal y como sostiene Clausewitz, cada parte trata de imponer a la otra su ley, sin embargo, en la guerra asimétrica y en el terrorismo, los contendientes tratan de aprovechar en su beneficio la "ley" del contrario. Es pues, no ya la antítesis del paradigma de Clausewitz, sino una visión inversa. Pero es también la lucha de las avispas frente al león que pasa por la dislocación social, la intimidación, la desmoralización de la sociedad y la eliminación del adversario mediante el atentado (Díaz de Villegas, 1963, p. 90).

La narración se hilvana sobre los atentados; con la elección de la víctima, se unen pregunta y respuesta, causa y solución, pero es sobre todo voluntad, impulso belicoso. El discurso se va construyendo y adaptando con cada acción. Al final lo que queda claro es el desencuentro, no su causa.

$\mathrm{Y}$ es que las narrativas no describen la realidad sino que la crean, generando el espacio ético necesario para la violencia: los terroristas precisan de una ética para poder convivir con la violencia de que son portadores. De no existir las narrativas pasarían de ser gestores de la violencia a incorporarlas a su vida degradándose ante el grupo y también ante sí mismos, a la condición de delincuentes, o peor aún, a la de psicópatas (Aznar, 2013, p. 4). Esto, a su vez, genera entre la población un vago deseo, una tendencia a perdonar hechos imperdonables porque el motivo había sido auténtico.

Las narrativas son victimistas, plantean unos orígenes míticos sobre la derrota al tiempo que crean un constructo esforzado y heroico; perder para ganar al decir de San Pablo. La lectura que hacen de los hechos en su fondo es pesimista (Aznar, 2012, p. 4). Con todo y por su distanciamiento de la realidad no puede resolver los problemas a los que atiende. Así, por ejemplo, se produce una transferencia de sacralidad - recaban para sí una fe cuasi religiosa ${ }^{-}$sin resolver el problema asociado a la trascendencia.

Además, resultan difíciles de penetrar, son refractarias, en el sentido de que solo consumen información de fuentes afines, una tendencia egocéntrica que puede acabar en el autismo y hacerlas perder por completo su contacto con la realidad. Y es que resulta muy dificil que acepten información, por válida que sea, que contradiga sus fines y supuestos. Son 
en este sentido autónomas y se sitúan dentro de ciertos límites al margen de la realidad convencional.

El resultado es un bucle melancólico (Juaristi, 1998), en la medida en que es incapaz de cerrarse y, perdida en el narcisismo, resolver su propia dinámica. Así, desencadenan un proceso que no solventan, porque la resolución es racional mientras el planteamiento emocional.

\subsubsection{Terrorismo e imagen}

Cualquier estrategia asimétrica es ante todo un discurso de impugnación; una impugnación del poder realizada primero ante la autoridad que lo utiliza, ante el propio ejército, ante su pueblo y, finalmente, ante la humanidad en su conjunto. Un discurso que permite al débil desafiar al fuerte, invitando a otros a seguir sus pasos, manteniendo la esperanza pues demuestra que aquel es vulnerable (González, 2009). Y es que el discurso de la guerra asimétrica deslegitima, porque una acción del débil sobre el fuerte presenta la fuerza de aquel como desproporcionada y abusiva.

El fotógrafo es un selector de la realidad, que utiliza lo particular para expresar lo general. La foto de un niño arrojando piedras a un carro de combate impugna el discurso del fuerte y cuestiona su causa.

\section{Figura 1. Fusilamientos}
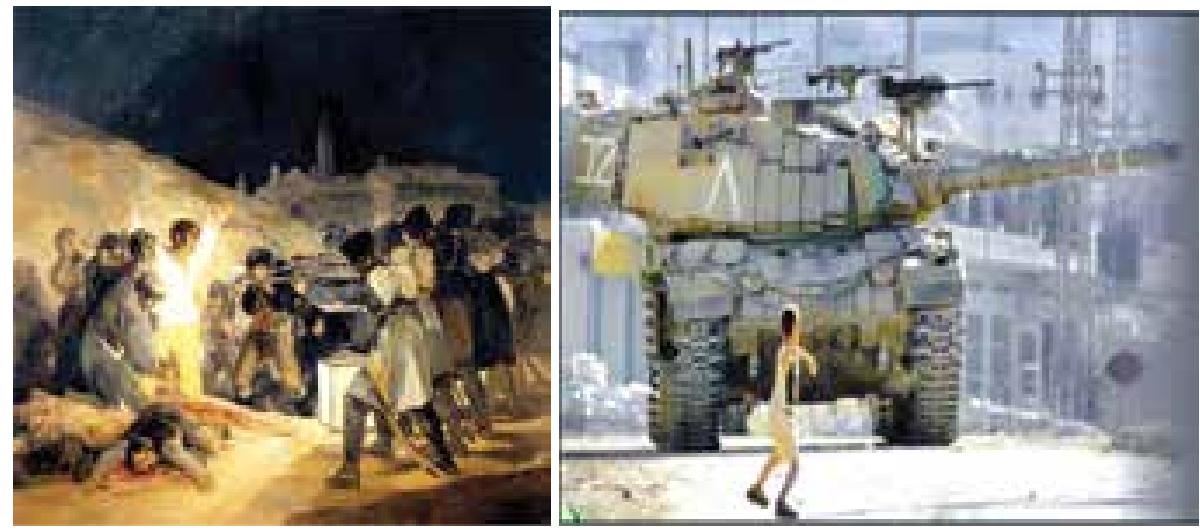

Fuente: Aznar (2012, p. 8). 
¿Cuántas ametralladoras más hay que montar al tanque para que derrote al niño? Desde el momento en que se toma la foto, la situación abandona el terreno de lo militar y se interna en lo mediático, y de allí salta al nivel de lo político. Con ello lleva la batalla a un plano no militar.

Lo que el fotógrafo no presenta, lo que no aparece en la foto no existe: el lugar hacia donde apunta el tanque, que no es al niño, no ha sido mostrado, por lo que es irrelevante, no forma parte del discurso, porque se integra en la acción militar y esta, aunque se presenta, no es objeto de la atención del público general, es subsidiaria, nadie se hace preguntas porque lo que cuenta es la imagen principal, el niño, el foco, la realidad explícita. La fotografía está dirigida principalmente a lo emocional no es para sesudos y documentados analistas cuyos escritos raramente son de interés para la opinión pública. Es una estrategia altamente eficiente.

El terrorismo con la precisión de un publicista buscando la máxima audiencia, calculando el impacto que pretende lograr, elige el marco de la fotografia, la presentación que en cada instante conviene, y la va variando atendiendo a la realimentación que recibe y al objetivo final que pretende. Eso requiere de imaginación, no de grandes medios.

¿Qué tipo de respuesta puede dar? La denuncia es el objeto de la acción. No cabe una respuesta en el terreno militar, hay que plantearla en otros planos. Así, frente a un ataque armado cabe realizar un reparto de alimentos, la construcción de una carretera, llamar a los padres del niño... Desde luego no se puede aceptar su envite ni el plano que han escogido para el enfrentamiento.

La fotografía es la imagen recíproca del cuadro de Goya Los fusilamientos de la Moncloa, el niño (activo) es sustituido por los prisioneros (pasivos) en colores vivos cuyo nombre, como el del niño, es conocido. Y el tanque (pasivo) con el cañón desfasado, es sustituido por el gris de los soldados a punto de disparar.

Ambas imágenes constituyen un discurso completo, el mismo, el de la impotencia y el de la injusticia (el conflicto israelopalestino en la web es una sucesión de este tipo de fotografías). La diferencia es que Goya lo hace después de la guerra para explicarla, para construir la historia, 
para juzgarla definitivamente; mientras la fotografía está concebida para influir en aquella y forma parte de la estrategia de una de las partes (Aznar, 2012, http://www.ieee.es/Galerias/fichero/docs_opinion/2012/ DIEEEO07-2012_GuerraAsimetrica_FA.pdf).

Estas fotos se alternan con otras de espectáculos de terror, de violencia, que se presenta como la respuesta a la injusticia de la otra parte. Represión y terror se integran así coherentemente en los discursos como las dos caras del dios Jano. El terrorismo exitoso siempre debe formar parte de una estrategia más amplia en cuyo vértice está la política (http:/ / www.ieee.es/Galerias/fichero/docs_opinion/2012/DIEEEO07-2012_ GuerraAsimetrica_FA.pdf).

El poder es imagen, plástica; es potencia que no acto. Y el terrorismo juega utilizando técnicas asimilables al trampantojo; por eso es ante todo efectismo, arte, ficción, teatro con el que se busca el definitivo secuestro de la imaginación (Aznar, 2012, http://www.ieee.es/ Galerias/fichero/BoletinesIEEE3/2016/boletinieee2.pdf).

Los atentados son una puesta en escena, escenarios diseñados con las medidas de una cámara para presentar lo particular como general y, mediante la emoción, manipular las conciencias y los temores haciendo que los espectadores no solo se integren en el escenario y sientan como próximas las amenazas terroristas, sino también para que asuman el papel que les es asignado. El coctel entre verdad (realidad), emoción y temor embota cualquier mente.

$Y$ es que las sociedades posheroicas son sociedades que viven en el presente, que no se sienten ligadas por el pasado y cuya aquiescencia es imprescindible en los conflictos que se hacen en su nombre a través de las decisiones de sus representantes electos.

Estas sociedades no disponen de tiempo para elaborar sus juicios, su información es no pocas veces deficiente. Una imagen en este contexto lo es todo, una explicación completa irrebatible y de una simplicidad extraordinaria, de ahí su valor en los conflictos. Una imagen a la hora de las noticias evita tener que leer un libro. ¿Cómo se puede explicar un conflicto como el de Kosovo con el tiempo se le asigna en los noti- 
cieros? (Aznar, 2012, http://www.ieee.es/Galerias/fichero/BoletinesIEEE3/2016/boletinieee2.pdf).

Los bombardeos mediáticos con consignas están destinados a destruir el pensamiento reflexivo con vistas a su sustitución por una sucesión de imágenes sin solución de tiempo y espacio elaboradas por la contraparte. Sustituir el discurso o forzar su reinterpretación desde nuevos parámetros es de la máxima relevancia.

No se trata de una colonización militar para el control de un territorio, sino de una colonización mental con vistas al ejercicio del control de una sociedad. La batalla está centrada sobre la cultura del enemigo y la victoria para el que sepa "resistir más tiempo, soportar más bajas y mantener su fe en la victoria” (Pizarro Pizarro, 2008: 465).

\subsubsection{Terrorismo y guerra asimétrica}

Desde una perspectiva instrumental, fijada en los medios, el terrorismo puede ser considerado como una forma de guerra asimétrica, con la que comparte muchos elementos en común, pero cuya estrategia no es decisiva en la medida en que no usa la violencia para destruir al enemigo tanto como para desacreditarlo; también puede ser insurgente, en ese supuesto su éxito radicaría en la movilización de la población concernida, todo lo demás supondría un fracaso (Aznar, 2010).

Así, sus objetivos son siempre limitados y orientados hacia el largo plazo. No pretende destruir el poder del Estado ni ocuparlo, sino que se conforma con forzar la negociación utilizando para ello a la opinión pública.

Otra diferencia con la guerra asimétrica y la guerra, radica en que por más que esta última se desarrolle en todos los planos y niveles posibles, el plano militar es el principal y es en él donde se dirime su resultado, con sangre. Mientras la guerra asimétrica pero sobre todo el terrorismo, se desarrolla en el plano político mediante una violencia que impregna los discursos para teñirlos en sangre; pese a ello son discursos, no batallas. 
Además, el terrorismo es una más de las posibles estrategias que pueden seguirse en una guerra. El terrorismo puede ser una estrategia de guerra asimétrica pero no toda guerra asimétrica es terrorismo; es más, el terrorismo puede estudiarse como un caso extremo de guerra asimétrica (Waldmann, 2006: 123) (Aznar, 2010, p. 202.

La diferencia entre guerra asimétrica y terrorismo se encuentra en la intensidad de las acciones, medidas por sus resultados, pero también y fundamentalmente, en la recurrencia de los actos; los terroristas no cuentan con la fuerza ni el número suficiente para poder ocupar un territorio y luchar abiertamente contra el Estado y el orden político que rechazan.

Además, la guerra asimétrica pretende ser resolutiva, es decir, pretende la derrota del enemigo para poder dictar las condiciones de la paz; es, pues, una guerra total para una de las partes, al menos. Sin embargo, el terrorismo tiene unos objetivos limitados pues no disponiendo de las condiciones materiales para imponer la paz - fruto de sus propios condicionamientos operativos- sólo la puede obtener en una mesa de negociación, en la que no puede pedirlo todo sino sólo conformarse con una parte.

Algunos de los autores referencia tampoco identifican al terrorismo como el rasgo más relevante de las guerras de Cuarta Generación, aunque estima dos de sus rasgos característicos; el primero es la búsqueda del colapso del enemigo en su retaguardia. El segundo es que se sirve de las potencialidades de su oponente en beneficio propio; así, utiliza sus leyes para protegerse al tiempo que deslegitiman al Estado ante sus ciudadanos (Fojón, 2006).

Guerrilla y terrorismo son dos formas irregulares de lucha. Pero en el caso de la guerrilla predomina aún la componente instrumental de la violencia mientras que en el terrorismo sirve a fines simbólicos y comunicativos (Waldman, 2006, p.123).

La guerrilla se emplea principalmente en zonas rurales, aisladas y empobrecidas, donde pueden operar en gran número e ir creciendo progresivamente hasta adueñarse de una porción de territorio, prefiere el 
hostigamiento al enfrentamiento directo, y su forma de operación aúna dispersión, concentración y movilidad (Van Creveld, 1991, p. 300).

De hecho autores como Mao identifican primero el terrorismo (sin consolidación territorial) y después la guerrilla (con consolidación territorial) como distintos estadios de evolución en la búsqueda de las condiciones objetivas hacia un conflicto convencional, hacia un choque de ejércitos ordinario, que sería el decisivo.

\subsubsection{La respuesta al terrorismo}

Lo primero que se precisa para resolver un conflicto, obviamente, es entenderlo, captar sus matices. Despreciar a un enemigo es el primer paso en el camino hacia la derrota; tenemos ya experiencia en ello. La violencia, la fuerza, no es su esencia por más que no pocas veces, cuando aparece, sea su manifestación más visible y eclipse todo lo demás. El elemento decisivo, el eje para el análisis, es el objetivo político al que sirve, la racionalidad que subyace oculta tras la violencia, su finalidad.

De lo expuesto cabe concluir que el problema no es propiamente de seguridad (aunque el arresto de los violentos es un paso adelante en la dirección correcta, como parte de una estrategia de contención) - el problema está resuelto de antemano, la clave no es ganar el conflicto, sino ganar la paz-, es principalmente político. Y el Estado Social y Democrático de Derecho, es un valor crítico a preservar, la piedra angular del discurso propio. Ciertamente la democracia enmascara una fuerza arrolladora: la voluntad concertada de millones de personas. Y sucede que perdidos en el fragor de la batalla a veces se olvida este hecho pese a su naturaleza capital porque concertar tantas voluntades es un proceso lento, lo que da la impresión a veces de ineficacia.

Y es que el terrorismo incita a la sobrerreacción, al exceso, a la pérdida de la racionalidad y al equívoco en la valoración del escenario; el terrorismo es provocación. El temor irracionalmente puede acabar por adueñarse de la población y obligar a aceptar las demandas de los terroristas o exigir una protección desmesurada a costa de otros riesgos e incluso en detrimento de la libertad. 
Es más, aceptar mantener el actual régimen de libertades en un marco de menos seguridad sería un paso adelante en la derrota del terrorismo y, paradójicamente, contribuiría a la restitución de la seguridad toda vez que asignándole un papel irrelevante, el terrorismo a medio plazo se convertiría igualmente en irrelevante.

Es imprescindible recuperar la iniciativa. No se puede ir a remolque de los sucesos que determina la contraparte, hay que seguir una estrategia y desarrollar los propios movimientos con independencia de los suyos. No existen estrategias reactivas que merezcan realmente el nombre de estrategias. Y en el siglo XXI la comunicación es esencial.

La lucha contra la violencia es una lucha entre narrativas que es imprescindible ganar. A fin de cuentas el terrorismo es una narrativa sangrienta. Por consiguiente, para enfrentarla a nivel estratégico y político debe existir en primer lugar un discurso propio, no completamente ajeno al de la contraparte, pero sí con un fundamento específico y vida autónoma que tenga bien presente la situación final deseada para poder conseguir el alineamiento de los objetivos y de las acciones. No disponer de él supone el desencaje de los planos táctico, operacional y político, con lo que poco puede lograrse; y deben formar parte de una cuerda más amplia que incluya lo operacional y lo político.

Este discurso propio no debe, no precisa, entrar en confrontación. Debe ser un discurso mejor, una oferta que sea capaz de asumir, en todo o en parte, la narrativa de los otros y disolver en ella sus demandas. La democracia se muestra así como una de las claves para conseguirlo pues tal es su función. A la vez debe actuar como un aglutinante de su grupo social propio para que este recupere su estimación y orgullo afectado por el cuestionamiento que se le hace y la siempre aparente ineficacia del Estado de Derecho; sin este elemento no cabe la victoria que es, en todo o en parte, una materia emocional y de percepción.

Hitler decía que "los partidos políticos se prestan a compromisos; las concepciones ideológicas jamás.” La razón es sencilla: Sí una ideología hace concesiones se desmonta, se desarticulan las líneas de pensamiento que sostiene, pierde su conexión con la razón y desarbola el imaginario deseado. La solución entonces pasa por una pedagogía mediática que 
obligue a tomar en consideración todo aquello que la narrativa sistemáticamente excluye y presente a las víctimas como lo que son, seres humanos, obligando a quienes apoyan tales acciones a asumir su responsabilidad por el daño humano generado, devolviendo el dolor al espacio social que lo produce, esto es, contrasocializando el dolor. Así, sin narrativa la violencia se transforma en un fenómeno irracional y ditirámbico (Aznar, 2012).

Y es que la forma con la que el terrorismo trata de separar al pueblo de su gobierno es desestabilizar al Estado intentando que éste muestre su naturaleza más coercitiva; así su respuesta se convierte en un revulsivo que ayude a la cristalización de las aspiraciones legítimas de la parte de población objetivo y sirva a su movilización. Es la espiral acciónreacción tan peligrosa para los Estados, en la que el terrorismo busca legitimar su causa.

El gran defecto del terrorismo es que, si no prospera en breve, si no sirve para la movilización social, no proporciona legitimidad; de hecho, la mayoría de los movimientos terroristas suelen desaparecer antes de un año de su aparición. Una vez que se alcanza, ésta va siendo relegada a un espacio cada vez más complementario conforme mejora la relación con respecto al adversario (Calvo Albero, 2004, p. 57).

La lucha contra el terrorismo no es sólo ni principalmente una lucha policial. Es ante todo un acto de la política; el conflicto es un encuentro de discursos y de éticas. El problema de las democracias es que la tradición democrática no condena la violencia en todos los casos.

Las nuevas guerras y el terrorismo son guerras de autor -Hannah Arendt, relaciona el terrorismo con el carácter anónimo de la sociedad moderna (Laqueur, 1980, p. 26)- suponen un retorno al hombre; la ética en este ámbito es trascendental para quienes tienen que convivir con la violencia y, consecuentemente, para quienes les combaten.

$\mathrm{Y}$ es que, como en todo humanismo, la ética es un elemento sustancial en los conflictos; hasta el terrorismo precisa de una ética pues quienes lo utilizan deben convivir con sus actos. En el campo de los fines todos son válidos; es indemostrable alguno que no lo sea. La ética pertenece a lo que es mensurable, que son los medios. 
La retórica que presenta como inútil la violencia es falaz. Siempre es útil para el que la utiliza porque calcula su utilidad y la juzga rentable. Sí en su cálculo se equivoca (normalmente por emplear una lógica lineal) eso es otra cosa; además muchas veces no se equivoca.

Fuché, diría con ocasión del secuestro y fusilamiento en Vincennes, del Duque de Enghien "fue peor que un crimen, fue una equivocación". Describía así un uso de la fuerza que puede ser simultáneamente un crimen y una equivocación, términos distintos y diferenciados que conviene encuadrar en todo análisis de un conflicto.

Paradójicamente a veces la naturaleza monstruosa de los crímenes pueda hacer olvidar la equivocación o incluso hacer que se justifique a sí misma por irrevocable lo que la dota de una fuerza creadora; es la "violencia partera" de la que ya hablaba Marx. Sí toda una sociedad ha guardado silencio ante las víctimas por puro temor, hace falta culparlas; al hacerlo indirectamente se santifica la causa que se dice asumir voluntariamente. El terrorismo consuma entonces el secuestro completo de la conciencia de la población.

Por otra parte y en otro sentido, su carácter equivocado pueda invitar a un más fácil perdón, pues admitir una equivocación es una forma de renegar de la maldad y salvar la causa, los fines a los que los medios han emponzoñado.

La utopía de acabar con las guerras implica simultáneamente una tautología, hacerle la guerra a la guerra y una contradicción pues, dada su naturaleza instrumental, se precisa de una fuerza coercitiva que debe ser, como mínimo, de un nivel equivalente al propio de las guerras en sí. Otro tanto cabe afirmarse de la guerra contra el terrorismo.

Como en toda estrategia militar, la respuesta militar hace que los terroristas puedan presentarse como militares y supone la equiparación de las partes, se les legitima. Y se benefician siempre de cualquier exceso.

También cabe la postura inversa, que sean los fuertes los que asuman los métodos de los débiles para enfrentarse a ellos. Encarna el peligro, en la lógica de Clausewitz, de hacer de un grupo terrorista un ejército, o de las Fuerzas Armadas unos terroristas; la aplicación de leyes de guerra a un terrorismo inconcreto no resuelve ese dilema (Aznar, 2011). 
Es precisamente en los valores, en lo que constituyen la fuente de la legitimidad, en lo que no se puede ceder porque ese es el envite real. Además, los fuertes no están preparados para aplicar esa metodología y no solamente porque sus sociedades no lo acepten, que también.

La contradicción que encarna el terrorismo está en que recaba para sí una legitimidad que la movilización popular no le concede y se prolonga en algunos casos, como el de ETA, durante 40 años, pese a haber dispuesto de asociaciones civiles, partidos políticos y hasta de representación parlamentaria sin dejar por ello de ser un mero grupo marginal. Son los riesgos de materializarse en vez de ocupar un lugar en la imaginación.

En su enfrentamiento con una fuerza superior, el terrorismo se presenta como la única estrategia racional que puede conducir a los oprimidos a la victoria; por consiguiente, la forma de superar esta contradicción es poner a disposición de las minorías medios políticos pacíficos para asegurar su resarcimiento, y de esta manera negar su legitimidad (Ignatieff, 2005: 11). La democracia como sistema de articulación de conflictos trata de absorber la frustración política experimentada para las partes en la búsqueda del bien general, se ve forzada a ceder en sus legítimas aspiraciones (Aznar, 2011).

Para ello deben establecerse cauces para la expresión del descontento sin necesidad del recurso a la violencia superando la correlación existente entre frustración y agresión (Robles, 2004, pp. 18-19). Se precisa de espacios que sirvan para la canalización del descontento de quienes pretenden cambiar el orden y les impida tomar las armas, incluso admitiendo la contestación social.

La contrapropuesta, en este caso pasa por un "proyecto sugestivo de vida en común" (Frías, 1999, p. 174). Conviene, además, desideologizarlo, privarlo de su discurso, para así poder criminalizarlo y convertirlo en una suerte de delincuencia común al tiempo que se refuerzan las instituciones locales, corrigiendo sus defectos y eliminando sus vicios de modo que unos pierdan legitimidad y otros, paralelamente, la ganen; hay, pues, que reforzar el Estado. Las réplicas extemporáneas tienen el riesgo de igualar peligrosamente a las partes. Es imprescindible preservar el sentido de comunidad. 


\subsection{Paz y terrorismo}

La palabra paz tiene la misma raíz que la palabra pacto. De hecho, el fin de la guerra sea la paz, encarna una contradicción dialéctica insuperable siempre que no se aniquile al enemigo, lo cual a su vez supone una contradicción ética igualmente insuperable, al menos en el siglo XXI y en Occidente.

Es más, la clave de las nuevas guerras, paradójicamente no está en ganar la guerra - el problema militar suele estar resuelto de antemano, sí Occidente se implica a fondo - sino en ganar la paz, en derrotar a la insurgencia y al terrorismo.

La clave, pues, vuelve a situarse en los discursos; en desmontar su narración, en transformarla, en desacreditar un monólogo que se alimenta de las respuestas, de los errores y de su peculiar aproximación a la realidad. Se trata de ofertar un discurso propio que incluya una propuesta de comunidad, impedir que la desconfianza progrese, corregir aquellos elementos susceptibles de serlo y socavar su narrativa mostrando sus contradicciones e inconsecuencias y su naturaleza deliberadamente sesgada (Aznar, 2012).

La paz es una solución de compromiso que se encuentra, permanentemente y por definición, en un estado precario que sólo el tiempo permite consolidar. Reconstituir la multitud de planos afectados por la conmoción del conflicto requiere de un periodo de tránsito y de buena voluntad (Aznar, 2012).

La solución siempre pasa por deshacer los planos que sirven para escenificar la diferencia, evitando una polarización que contribuya a la construcción de las categorías amigo enemigo en torno a ella, resaltar lo común y respetar lo diverso, no ver en el diferente a un enemigo. Esto es, se basa en la pedagogía.

Una pedagogía que precisa de ideas, de reiteración, de un tiempo de reflexión (incluso de generaciones), de medios fiables a través de los que hacer llegar el mensaje, de estudio. Sin pedagogía, sin perseverancia, sin convencimiento, no se puede estabilizar el área sobre las que se ha 
intervenido militarmente. Pero la pedagogía no puede estar orientada hacia uno mismo sino, una vez definidos los objetivos y el mensaje que se pretende hacer llegar, debe dirigirse hacia el otro y tomarle en consideración. No existen métodos universales, salvo la violencia.

Occidente cuando actúa ofrece sus soluciones, elaboradas desde su cultura, desde sus apriorismos y prejuicios. Soluciones que muchas veces no terminan de encajar en la sociedad en que se ponen en práctica, no son la solución que ellos ven para sus propios asuntos.

Hay que tener mucho cuidado a la hora de trazar las líneas de separación, de definirse, de hecho es mejor no hacerlo, la definición excluye al otro. El reduccionismo, la simplificación, la dicotomía, no son acertadas, ni siquiera son inteligentes. Es preciso integrar no excluir, fortalecer lo común, lo que une y buscar simultáneamente que los pueblos elaboren sus propias soluciones.

La clave está pues en reforzar el Estado, dotándolo de medios para que atienda eficazmente al desarrollo de su misión; y es que el problema a veces no es el poder de los terroristas sino la debilidad del Estado que es expresión a su vez de la debilidad de la sociedad, donde se sitúa el eje del problema. Se trata, en primer término, de restituir la confianza a la comunidad, para tratar después de dotar de densidad a las sociedades, desarrollar sus tejidos y fortalecer las instituciones, promoviendo la buena gobernanza sin exclusiones.

La reconstrucción de las estructuras de gobierno, permite convertir un problema militar en un problema policial e interno. Es pues más eficiente, libera de responsabilidades a terceros y proporciona respuestas plenamente adaptadas a la situación, disminuyendo la desconfianza. De esta manera, la carga de la respuesta recae sobre la propia sociedad que es la que atiende a sus asuntos y puede resolver el problema en el marco de su cultura y sin tener que atender a los condicionamientos propios de sociedades y culturas ajenas.

Debe tenerse en cuenta que acabar con el terrorismo, no es a menudo acabar con su historia, liquidar la narrativa que ha generado. Otros pueden venir en el futuro presentándose como sus continuadores y re- 
clamar la legitimidad de aquellos. Una legitimidad, nueva distinta y más poderosa una vez que la sangre ha dejado de correr por las calles, se ha secado y las víctimas han desaparecido del escenario.

Es imperativo en la paz hacer justicia a las víctimas y, sobre todo, acabar por completo con la narrativa, haciendo que esta asuma la sangre que ha derramado y no sacrificar el futuro por un presente más fácil.

La participación de elementos locales, el empoderamiento, legitima el conjunto de la operación y es garantía de su continuidad al tiempo que permite una mejor adaptación de las decisiones al entorno y la formación y responsabilidad de quienes las adoptan.

La apuesta también debiera ser apoyar el fortalecimiento de la sociedad civil y amparar el desarrollo institucional, y no la mera celebración de unas elecciones que presentadas en Occidente como un hito, pueden no contar con una valoración similar en la cultura que las acoge.

Sin una sociedad civil sólida no cabe la democracia, cuyo ejercicio real requiere además de las condiciones adecuadas (la democracia no puede volver a traer la polarización ni el maltrato de las minorías; es el gobierno de una mayoría que respeta a las minorías). Todo ello necesita de tiempo, de pedagogía, de reconocimiento del otro; un tiempo que permite que se sellen las heridas que se han hecho presentes a veces para magnificar unas diferencias de orden menor, que se reflexione y resurja la comunidad como proyecto de futuro común.

\subsection{El fracaso del terrorismo global. Al Qaeda y Daesh}

El terrorismo hasta ahora había sido un fenómeno específico de un concreto marco, de una única cultura. Hay un terrorismo trasnacional que es aquel cuyas bases están en un país y desarrolla toda o parte de su actividad en otro. Un terrorismo internacional que es aquel cuya agenda es local y se desarrolla en distintos países atendiendo a su agenda esto es, a sus finalidades locales. El terrorismo global es el que cuenta con una agenda para el mundo y, además se desarrolla por todo el planeta (Reinares, 2003, p. 11) 
La globalización ha hecho del terrorismo intercultural un fenómeno cada vez más frecuente. Comprender el terrorismo intercultural es aún más difícil en la medida en que sus efectos tienen que tener en cuenta a las sociedades de su público y de su objetivo. Por eso desecha a las sociedades sobre las que se actúa; ese desprecio hace posible los atentados indiscriminados (Aznar, 2013).

Asume así lo que Hitler apuntaba "la primera de las condiciones del éxito consisten la aplicación perpetuamente uniforme de la violencia” y realiza, de modo sistemático e imprevisible, actos de violencia que producen un impacto psicológico de consecuencias muy superiores a las puramente materiales, para condicionar el pensamiento de la población o modificar la actitud de las elites (Reinares, 2003, p. 16). Con ellos se transmite un mensaje y se dota de credibilidad a la amenaza, obligando a realizar un esfuerzo y elevar los niveles de alerta Aznar, 2012).

Los atentados del 11-S parecen haber sido concebidos por un publicista proporcionando a la organización Al Qaeda una visibilidad no acorde con sus capacidades militares reales. Se convirtió con ello en el banderín de enganche de la contestación, de los descontentos con el sistema.

No obstante, aunque contó desde el principio con la simpatía de amplios sectores sociales del mundo musulmán que veían en ellos a sus vengadores, no llegaron a pasar de este punto. No consiguieron generar el efecto de movilización a nivel mundial que pretendían.

La organización era una suerte de franquicia global que tomaba su legitimidad de las fuerzas locales - aun manteniendo un núcleo duro de profesionales- que se definían como parte de la organización y que, a su vez, veían reforzada su legitimidad por el halo de aquellas imágenes. Su forma de actuar se basa en efectuar atentados que iluminen la dirección a seguir a las distintas organizaciones independientes, incluso a particulares (convocados a hacerlo, por ejemplo, mediante atropellos), que puedan llevarlos a cabo.

Pero el Islam que representaba era inamovible y no casaba con la cultura específica de muchos países musulmanes. Podía representar sus 
anhelos, sus odios o ser sus verdugos pero no podía representarles a ellos. Su Islam era un Islam concreto, extremo, intolerante.

De hecho su violencia, en parte, estaba orientada a la transformación de la sociedad. Y no pocas de sus víctimas, tal vez la mayoría, han sido musulmanes. Esta postura acabó por perjudicarles, hasta el extremo de verse combatidos por quienes, como en Irak, les habían acogido previamente.

La cuestión es que, como se ha dicho, sí los partidos pueden hacer concesiones, las ideologías no y una cosmovisión como la apuntada por Al Qaeda mucho menos. Sin compromiso, sin la armonización, no cabe el encuentro, la vertebración y la incorporación a la masa crítica. La falta de cintura política de los radicales impidió la agregación al cuerpo de los descontentos de no pocos.

Si a eso le añadimos, como se ha visto, un proceso de globalización incompleto, que hasta el momento impide la existencia, propiamente dicha, de una agenda política global, entenderemos porque el terrorismo global nunca dejó de ser local, porque su agenda lo era y porque siempre se daba en un país, o a lo más en una subcultura y siempre para lo mismo, para hacerse con el poder al nivel considerado.

$\mathrm{Y}$ es que el terrorismo no es poder es ficción de poder; el poder es potencia y para ejercitarse como tal precisa de un marco concreto. Y el marco global no se encuentra definido porque la globalización como proceso no ha terminado; existe un marco local, provincial [...] pero lo global no existe como un espacio estructurado para la proyección del poder. Aun no se daban, ni se dan, las condiciones objetivas en este ámbito.

En consecuencia, no tenía ni capacidades ni medios para llevar a cabo sus políticas, el marco que habían escogido no sólo era excesivo sino que todavía no se encontraba completo y, además, su Islam no representaba el del todo los musulmanes.

No ha habido maridaje entre los distintos grupos terroristas, no ha habido una coordinación, ni una actuación concertada más allá de rituales como la beia (un acto tradicional de homenaje y subordinación). 
Como resultado, perdió la iniciativa, se produjo después el estancamiento "militar" y, finalmente, la inoperancia de una organización de la que ya sólo queda el nombre y el pasado. Su principal éxito, y no es poco, es haber sido capaz de generalizar el uso de la palabra "yihadista" que sirve de apellido y mínimo común denominador a distintos movimientos locales, dotándoles de una mínima vertebración y generando sinergias a nivel global. La dinamización de estos movimientos ha incrementado sensiblemente su número y generando con ello una suerte de "alqaedismo" sobre la base de asociaciones de todo tipo y franquicias. Su número, según Seth Jones, ha pasado de 3 movimientos en los años noventa a casi un centenar en la actualidad.

Es más, entre 2010 y 2013, se ha producido un incremento del 58\% en el número de grupos sobre todo en el Norte de África, el arco saheliano y Oriente Medio; la presencia de Al Qaeda y sus filiales ha pasado de 8 teatros de operaciones en 2008 a 16 en la actualidad. Pero la debilidad de su aparato central se encuentra entre las causas del surgimiento del Daesh que ahora consigue la adhesión de grupos próximos a aquella (Aznar, 2012).

Así, la acción de Occidente contra al Qaeda ha acabado por hacer a las franquicias que dio lugar más visibles que al propio órgano central sumergiendo a la organización en un magma de organizaciones yihadistas. Al Qaeda sería el tótem en el que todas ellas recurren y su única victoria sería haber resistido.

En los lugares que el Daesh controla trata de afirmarse recolectando tasas, impuestos, imponiendo multas de tráfico..., tratando de dar a la población todos los servicios propios de un Estado. Si Ben Laden centraba su discurso en recuperar las tierras del Islam, el Daesh aspira a romper cruces e instalarse en Roma, llevar el conflicto a su dimensión última y permanente en espera del fin de los tiempos.

El Daesh ha aparecido en un espacio vacío geopolítica y geográficamente en el centro de pentalasia como resultado de las fuerzas que convergen en él. Esto es, la falta de un liderazgo suní claro- diferenciado entre Arabia Saudí, Egipto, Turquía y el lejano Pakistán - y su enfrentamiento con el mundo chiita en un espacio controlado por un Estado 
desarbolado y cuya autoridad no es aceptada por todos sus ciudadanos, miembros enfrentados de ambas ramas del Islam.

Sí al Qaeda es difícil de combatir militarmente, el Daesh, por ubicarse geográficamente y practicar un modelo híbrido que combina insurgencia y terrorismo, lo es menos. Su proclamación lo liga a un territorio; de colapsar, su existencia como grupo terrorista en la misma forma y términos que al Qaeda no sería posible, la beia perdería su vigencia, la obligación de emigrar a la región desaparecería y la Sharia dejaría de estar en vigor. Es poco probable que tropas chiitas puedan conseguirlo, pues son ampliamente rechazadas en la región y podría alterar el escenario presente en muchas sociedades árabes del entorno que difícilmente se avendrían a ello. No obstante, en la resolución del problema convendría tomaran parte todos los países de la región, Irán incluido, para conservar sus equilibrios.

Pero si puede ser contenido con estrategias de negación (como los bombardeos aéreos). La eventual invasión tiene el riesgo de conducir a un escatológico enfrentamiento en la mítica Dabiq y corre el riesgo de alterar los frágiles equilibrios de la zona. Dejándoles operar libremente por el contrario, se puede acabar por provocar la implosión de un régimen víctima de sus contradicciones internas que además se encuentra aislado y que difícilmente podrá alterar tal circunstancia. Mediante políticas de contención, esto es impidiendo su expansión se puede probar el fracaso de su proyecto político-religioso y vacunar la región frente al aventurerismo de este corte.

Simultáneamente, hay que reforzar el Estado tanto en Irak como en Siria - resolver la guerra que vive este país sería un gran paso adelante, acotaría el problema y haría dudar de las posibilidades reales del Daesh a su grupo de apoyo, aunque pactar con el Diablo siempre tiene sus costos - de un modo diferenciado y en régimen de geometría variable, retejer sociedades fracturadas, fortalecer y ensanchar las instituciones y promover una cultura de tolerancia. Es una tarea ímproba que cuanto menos llevará una generación porque implica un cambio de modelo cultural. Los grandes proyectos, y este lo es, llevan tiempo y esfuerzo. El pensamiento mágico es inaceptable. 
Para ello es imperativo hacer pedagogía. Por difícil que pueda parecernos, ellos la hacen trabajando concretos segmentos de las sociedades musulmanas. Las narrativas no son un hecho neutral, ni siquiera son un hecho objetivo son un poder, una herramienta de persuasión política más potentes incluso que los argumentos y que resulta muy difícil de desactiva.

Consecuentemente, hace falta una cuidada estrategia mediática y pedagógica que tenga muy presente las bases antropológicas de la audiencia deseada (previamente definida) y que se una a la estrategia militar y sea coherente con el discurso propio; las incoherencias son sencillamente humanas aunque inexcusables. Una estrategia que sirva para reforzar la narración, supere y desmonte la del contrario mostrando sus incongruencias y saltos argumentales, sin por ello desmantelar el propio discurso que no puede en ningún momento comprometer su carácter de relato autónomo (Aznar, 2013).

En este contexto, no hay que perder de vista la ya citada falta de adecuación de las organizaciones yihadistas al marco social y cultural en el que operan y su incapacidad para propiciar su transformación real en las claves propias del Islam que propugnan. Y el Daesh tiene aún menos cintura que Al Qaeda; no obstante cuenta con la ventaja de instalarse en la zona de la que surge su base ideológica; es más, viene a coincidir con la práctica religiosa de segmentos significativos de musulmanes de la zona. Así, por ejemplo, utilizan en las escuelas bajo su control libros de uso corriente en algunos países de la región.

Un escenario peligroso sería la actuación concertada de Al Qaeda y el Daesh, pero tampoco se debe descartar un enfrentamiento entre ambas, aunque es mucho más probable lo primero que lo segundo dado que comparten un suelo doctrinal común.

Tampoco se debe magnificar la amenaza que supone para Occidente estrategias como la de los lobos solitarios, de valor más mediático que militar, toda vez que no incorporan una retórica política mínimamente sólida para Occidente y los daños que ocasiona son limitados. Cosa distinta sería que estas organizaciones fueran capaces de hacerse con armas de destrucción masiva, tarea esta compleja pero que sin duda estarán acometiendo (Aznar, 2013). 


\subsection{Conclusión}

Las guerras son hechos sociales, expresiones culturales, una forma de relación y un diálogo con un suplemento de violencia. Y el terrorismo se plantea en términos de guerra. Cuando la guerra es dentro de nuestro mundo es solo un choque de voluntades que se resuelve en el campo de batalla; cuando la guerra es entre dos mundos además puede ser un choque de identidades. Eso es lo que conviene evitar a cualquier costo.

El campo de batalla puede determinar que la voluntad es más fuerte, puede destruir la voluntad de seguir luchando del adversario. La victoria de una de las partes puede desplazar en el tiempo un conflicto pero no resolverlo; el derrotado volverá a tomar las armas en cuanto pueda ya que el campo de batalla no puede reconstruir su futuro como tampoco puede hacerlo con su identidad o su reinterpretación (González Martín, 2009). Esa es una razón para la insatisfacción tras el combate, no hay un futuro mejor para la cultura vencedora, porque no se contempla ningún futuro alternativo fuera de esa cultura. Esto es, la raíz del problema no es militar, el plano militar es un teatro secundario. Las respuestas, la paz, hay que ir a buscarla en otro sitio.

En este contexto, el modelo asimétrico de guerra y con ello el terrorismo se inclina más por la dimensión psicocultural de la guerra, entendida por la comprensión del enemigo, su psicología, sus motivaciones y la idiosincrasia cultural de su modo de combatir para proceder al encaje de la guerra en el contexto de las realidades culturales, económicas y tecnológicas. Se vuelve otra vez a que la guerra es una forma de relación.

La guerra y con ella el terrorismo, supone un enfrentamiento de poderes (o de imagen de poder) y no es un acto ético, ni justo, ni legal [...] ni siquiera militar; y cualquier análisis que se emprenda desde estos planos sin resultar falso es incompleto e induce a la adopción de decisiones erróneas. Es un acto político que, atendiendo a su dimensión integral, supera y desborda cualquiera de los planos considerados. Es más que un acto económico y mucho más que una sucesión de atentados.

Es por encima de todo, un instrumento de la política; se encuentra al servicio de otros fines. Se ha dicho, la finalidad de la guerra es la paz 
entendiendo esta como la nueva situación política generada tras el conflicto. Por consiguiente, en todo conflicto debe existir una clara subordinación de la acción militar a la acción política, porque sin control político se puede llegar a la desmesura de una guerra absoluta y sin sentido. Como Clausewitz (1999: 183) decía:

el acto primordial, el principal y más decisivo del juicio que ejercen el estadista y el general, es comprender rectamente la guerra que emprenden, no tomándola por algo o desear convertirla en algo totalmente imposible por su propia naturaleza.

La cuestión es sí la guerra del siglo XXI es asimétrica con toda su panoplia de estrategias. La guerra de Georgia rompió el mito de que los Estados habían abandonado la escena internacional y que las democracias (cualquiera que sea el grado de estas) no hacían la guerra. El pasado siempre puede retornar y es imprudente olvidarlo.

El 11-S no supuso un aumento significativo de la conflictividad a nivel global, aunque sí pudo acentuar alguno de los conflictos presentes y contribuir a la visualización de otros. El hecho decisivo de los últimos 50 años es y seguirá siendo la Caída del Muro. Con todo, puede concluirse que sí bien todavía es posible que se dé algún destello del terrorismo, incluso un destello nuclear, el mundo es hoy un lugar más seguro que en el pasado. 